\title{
Mediastinal abscess complicating esophageal dilatation: a case report
}

\author{
Doaa M. Magdy, Shereen Farghaly, Ahmed Metwally
}

\begin{abstract}
Mediastinal abscess is a rare yet emergent infectious complication of the thoracic cavity following balloon dilatation of the esophagus. Early diagnosis and management could avoid its poor outcome. A 20-year-old man with esophageal stricture underwent balloon dilatation. A mediastinal abscess developed 2 weeks after procedure. Computed tomographic chest helped in diagnosis and guiding approach of management. Surgical drainage and debridement of the abscess were performed. Surgical treatment combined with systemic antibiotics was effective, leading to remission of the abscess. Mediastinal abscess should be considered as a possible infectious complication after upper endoscopy. Computed tomographic scan is a mandatory imaging modality to enable early diagnosis. Aggressive treatment including surgical drainage combined
\end{abstract}

\section{Introduction}

Benign esophageal strictures had been reported owing to several causes, for example, gastro-esophageal reflux, radiation therapy, esophageal resection, ablative therapy, or the ingestion of a corrosive substance [1]. Treatment of most strictures typically involves endoscopic dilation using bougies or balloons. Despite advances in endoscopic equipment and dilators which have improved the safety of esophageal dilation, infectious complications still have been reported even in the most experienced hands [2]. The most dreadful complication associated with esophageal dilatation is esophageal perforation [3]. The problem is that symptoms and signs of early esophageal injury are vague and nonspecific [4], which in its part can lead to catastrophic presentation of the patient. Thus, awareness of the complications associated with dilation permits early recognition and reduces morbidity and mortality [2].

We reported a case of mediastinal abscess complicating upper gastrointestinal (GI) endoscopy for treatment of esophageal stricture, which was successfully treated with prompt surgical drainage.

\section{Case report}

A 20-year-old male had a history of dysphagia since childhood and diagnosed using upper GI endoscopy as congenital esophageal stricture for whom repeated balloon dilatation was done. The patient underwent an uneventful esophageal dilatation via a balloon (Olympus GIF-H260) to relieve symptoms. The with medical management is the treatment of choice that may prevent catastrophic outcome.

Egypt J Bronchol 2019 13:570-573

(C) 2019 Egyptian Journal of Bronchology

Egyptian Journal of Bronchology 2019 13:570-573

Keywords: balloon dilatation, mediastinal abscess, mediastinoscope

Department of Chest, Faculty of Medicine, Assiut University, Assiut, Egypt

Correspondence to Doaa Magdy, MD, Chest Diseases and Sleep

Medicine, Chest Department, Faculty of Medicine, Assiut University

Hospital, Assiut, 71111, Egypt. Tel; 01006261010

e-mail: doaamagdy_2020@yahoo.com

Received: 27 January 2019 Revised: 4 January 2019

Accepted: 12 May 2019 Published: 25 October 2019

patient was discharged without complications 1 day after the procedure.

Two weeks after upper GI endoscopy, the patient presented to the local emergency department complaining of shortness of breath, cough with yellowish scanty sputum, and fever. A chest radiography was done for him (Fig. 1a), and a nonspecific antibiotic was prescribed for him. Three days later, the patient presented with progressive dyspnea and persistent continuous fever not responding to antibiotic or antipyretic. On admission, the patient was evaluated. The patient looked pale and toxic, had a body weight of $60 \mathrm{~kg}$, blood pressure of $100 / 60 \mathrm{mmHg}$, heart rate of 110 beats/min, respiration rate of $35 \mathrm{breath} / \mathrm{min}$, and body temperature of $40^{\circ} \mathrm{C}$. Normal chest examination was reported.

Laboratory tests showed white blood cell count of $20 \times 10^{4} / \mathrm{ml}$, hemoglobin concentration of $10 \mathrm{~g} / \mathrm{l}$, hematocrit of $30.2 \%$, and platelet count of $136 \times 10^{11} / 1$. Chest $X-$ ray was repeated showing broadening of the upper mediastinum (Figure 1B). A computed tomographic (CT) scan of the chest revealed a multiple air spaces in the mediastinum in retrosternal space and around the esophagus (a picture compatible with a mediastinal abscess) Figure 2.

This is an open access journal, and articles are distributed under the terms of the Creative Commons Attribution-NonCommercial-ShareAlike 4.0 License, which allows others to remix, tweak, and build upon the work non-commercially, as long as appropriate credit is given and the new creations are licensed under the identical terms. 


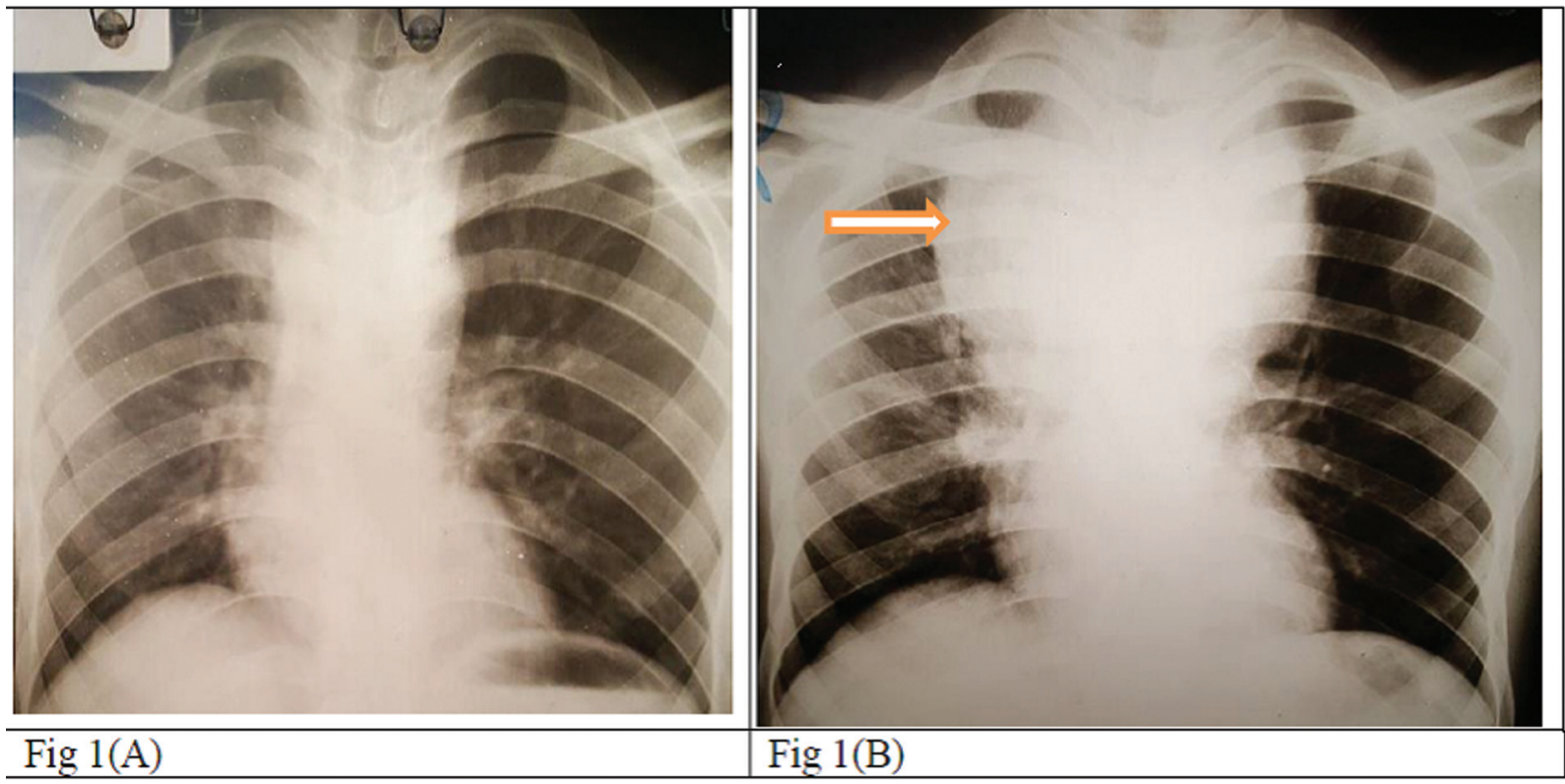

(a) Chest radiography before the esophageal dilatation, and (b) chest radiography 2 weeks after the procedure, showing wide mediastinum with homogenous opacity in the right chest obscuring the right border of heart and trachea.

Figure 2

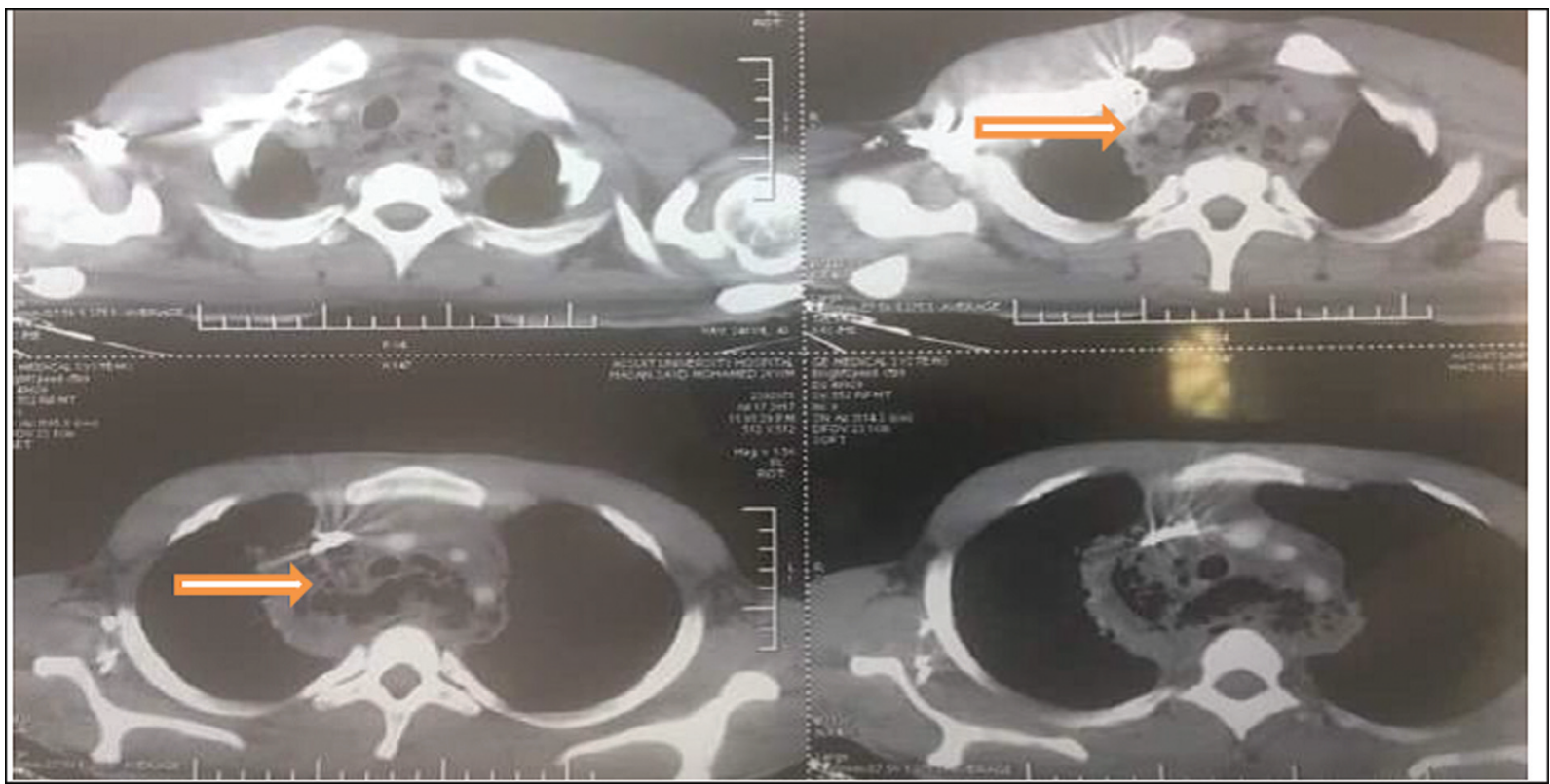

Computed axial tomographic scan of the chest showing a well-defined mass with air collection behind the anterior chest wall.

On the second day of admission, cardiothoracic surgeons were consulted and mediastinoscopic debridement and drainage of abscess cavity was performed (Fig. 3). Drainage tube was placed in the cavity of the anterior mediastinal abscess. Gram staining of the pus aspirated from the anterior mediastinal abscess revealed streptococcus pneumonia and Diphtheroids. The patient's general condition gradually improved with antibiotic treatment and drainage, and he was discharged on antibiotics after 15 days following the procedure.

\section{Ethics}

This study was approved by local ethics review committees, and the patient gave informed consent. 
Figure 3

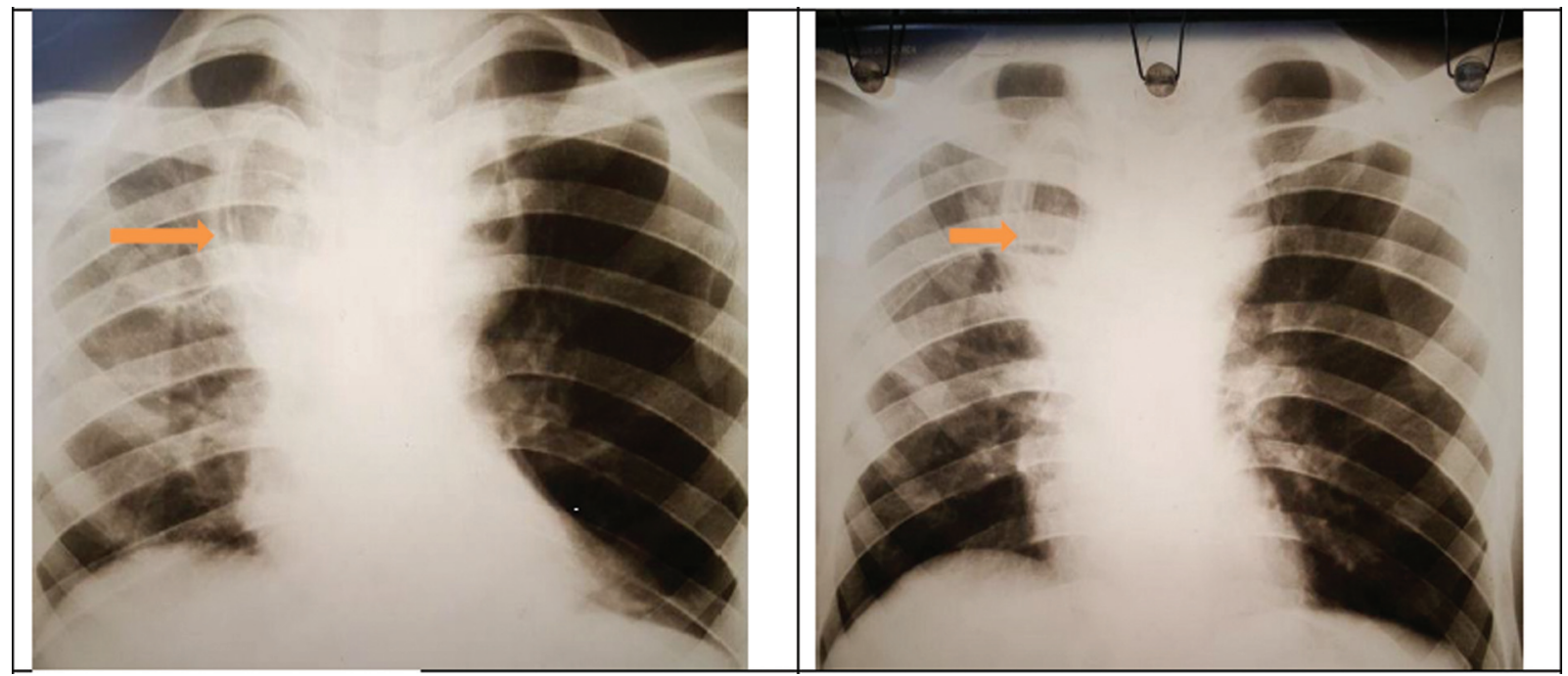

Chest radiography showing the opaque drainage tube in the abscess cavity.

\section{Consent}

Written informed consent was obtained from the patient for publication of this case report and accompanying images.

\section{Discussion}

The mediastinum is a rare site for infection, but sometimes extension of infection from nearby structures, rupture of the tracheobronchial tree, or esophageal perforation can cause acute mediastinitis or mediastinal abscess. Mediastinal abscess has been recorded in $\sim 1 \%$ of patients presenting with esophageal perforation [5]. Infection was possibly caused by direct contamination of the mediastinum with the esophageal bacterial flora. Thus, anaerobes such as Streptococcus viridans and fusiform rods were frequently isolated from cases of acute mediastinitis secondary to esophageal perforation [6], and that was clearly demonstrated in our case. Early diagnosis is mandatory as mediastinal abscess can lead to rapid and fatal deterioration of the patient's condition. Unfortunately, the clinical symptoms are often atypical and misleading [5].

Radiological investigations could be helpful. Conventional chest radiography may show the boarding of upper mediastinum and loss of its normal contours. Pneumomediastinum might be also observed. However, definite air spaces collection in the mediastinum could be detected by $\mathrm{CT}$ of the chest. CT chest could also identify the extent of soft-tissue infiltration and the optimum site for drainage of the mediastinal abscess [7].
Surgical drainage and appropriate antibiotic therapy are considered the cornerstone of management of a case of mediastinal abscess [8]. Both the location and extent of abscess are considered as important factors in determination of management. In this case, mediastinal abscess was in anterior rand upper mediastinum, thus transcervical drainage had been done. However, thoracotomy or subxipoid incision is recommended for extensive subcarinal abscesses [9]. Recently, several investigators had shown videoassisted thoracoscopic surgery to be a successful alternative to open methods in mediastinitis management from multiple etiologies. Such therapies may be preferable to more aggressive methods owing to reduced risk of complication, less pain, and more rapid recovery [10].In conclusion, mediastinal abscess should be considered a possible even if rare complication after upper endoscopy. Close monitoring for the development of signs and symptoms of infection following endoscopy is essential. CT scan is a mandatory imaging modality to enable early diagnosis. Aggressive treatment including surgical drainage combined with medical management is the treatment of choice that may prevent catastrophic outcome.

\section{Acknowledgements}

The authors wish to express their gratitude to the patient who kindly agreed to participate in this research.

\section{Financial support and sponsorship}

Nil. 


\section{Conflicts of interest}

There are no conflicts of interest.

\section{References}

1 Marks RD, Richter JE. Peptic strictures of the esophagus. Am J Gastroenterol 1993; 88:1160-1173.

2 Egan JV, Baron TH, Adler DG, Davila R, Faigel DO, Gan SI, et al. Standards of Practice Committee, Esophageal dilation. GastrointestEndosc 2006; 63:755.

3 Lan LCL, Wong KK, Lin SCL, Sprigg A, Clarke S, Johnson PRV, et al. Endoscopic balloon dilatation of esophageal strictures in infants and children: 17 years' experience and a literature review. J Pediatr Surg 2003; 38:1712-1715.

4 Wu JT, Mattox KL, WallJr MJ. Esophageal perforations: new perspectives and treatment paradigms. J Trauma Acute Care Surg 2007; 63:1173-1184.
5 White CS, Templeton PA, Attar S. Esophageal perforation: CT findings. Am J Roentgenol 1993; 160:767-770.

6 Brook I, Frazier EH. Microbiology of mediastinitis. Arch Intern Med 1996; 156:333-336.

7 Karnath B, Siddiqi A. Acute mediastinal widening. South Med J 2002; 95:1222-1225.

8 Son HS, Cho JH, Park SM, Sun K, Kim KT, Lee SH. Management of descending necrotizing mediastinitis using minimally invasive videoassisted thoracoscopic surgery. Surg Laparosc Endosc Percutan Tech 2006; 16:379-382.

9 Isowa N, Yamada T, Kijima T, Hasegawa K, Chihara K. Successful thoracoscopic debridement of descending necrotizing mediastinitis. Ann Thorac Surg 2004; 77:1834-1837.

10 Nakamura Y, Matsumura A, Katsura H, Sakaguchi M, Ito N, Kitahara N, et al. Successful video-thoracoscopic drainage for descending necrotizing mediastinitis. Gen ThoracCardiovasc Surg 2009; 57:111-115. 